\title{
1
}

\section{TRABALHO E SOCIABILIDADE: A ATUALIDADE DOS FUNDAMENTOS ONTOLÓGICOS*}

\author{
Adrianyce A. Silva de Sousa \\ Letícia Batista da Silva
}

\section{INTRODUÇÃO}

e se eu morrer vem outro em meu lugar e se eu morrer vão me condecorar e se eu morrer será que vão lembrar e se eu morrer será que vão chorar e se eu morrer e se eu morrer e se eu morrer e se eu morrer chega de ser subjugado subtraído subnutrido

[... sub-infeliz

mas essa estória eu volto a repetir aconteceu numa cidade muito longe daqui que tem favelas que parecem as favelas daqui que tem problemas que parecem os problemas daqui "Numa cidade muito longe daquil" - Acyr Marques, Arlindo Cruz

Cleonice $^{1}, 63$ anos, trabalhou como doméstica numa casa no Leblon, Rio de Janeiro, por 20 anos. Todos os dias de segunda a sexta-feira, ela saía do município de Miguel Pereira, na região serrana do Estado, e

\footnotetext{
${ }^{*}$ DOI - 10.29388/978-65-86678-37-6-0=f.23-48

${ }^{1}$ Disponível em <https://g1.globo.com/fantastico/noticia/2020/03/22/uma-pessoa-muitobatalhadora-diz-sobrinho-de-empregada-domestica-que-morreu-de-coronavirus.ghtml: $>$. Acesso em: 06 out. 2020.
} 
percorria mais de 100 quilômetros para chegar ao bairro nobre da cidade maravilhosa. Aos fins de semana, retornava para casa em Miguel Pereira. Numa segunda feira do mês de março deste ano, Cleonice que era diabética e hipertensa, estava no trabalho quando começou a passar mal. Um parente foi ao local, chamou um táxi e a levou para um hospital público em Miguel Pereira. O primeiro diagnóstico apontou para infecção urinária. Na manhã seguinte, ela apresentou quadro de intensa dificuldade respiratória e faleceu. Dois dias depois foi confirmado o óbito por COVID-19. A empregadora de Cleonice havia retornado recentemente de uma viagem para a Itália, país que enfrentava no início do ano uma explosão de casos do novo coronavírus.

No meio da pandemia a trabalhadora doméstica precisava estar lá porque a "patroa" mandou. Esse era mais um dia na vida de Cleonice que "livremente" "escolheu" aderir ao contrato de trabalho. Quantas Cleonices mais não puderam se preservar e preservar suas famílias? No Brasil, de certo, uma imensa maioria da população, esteve e está na tensão de pegar ônibus lotados para atividades que não podem parar e, para uma sobrevivência que não pode esperar. Mulheres e homens que precisam comer, vestir-se, morar, no sustento de si e da família, vendem sua força de trabalho em condições cada vez mais adversas. A pandemia de COVID-19 escancarou o que já se desenvolvia quase que como um impulso vital: a centralidade da venda da força de trabalho no capitalismo submete uma massa inumerável da população a condições deletérias para conseguir satisfazer as suas necessidades.

Felicidade, prazer, criatividade, autonomia são luxos que nem, às vezes, fora do desempenho das atividades é possível ter acesso e usufruir de bens e serviços. Nosso pressuposto é de que está cada vez mais aprofundado o processo de alienação e reificação do trabalho no capitalismo. É isso que, a nosso ver, reafirma a relevância do retorno mediado a categoria trabalho, em seus fundamentos ontológicos, atualizando o sentido da sua plena realização no oposto ao que se coloca como alternativas de emprego e empregabilidade na sociedade atual. Ao mesmo tempo, se pelo ato do trabalho, a existência humana se generaliza também é importante retomar a problemática da alienação e da reificação como funda- 
mentais para apreender as formas contemporâneas assumidas pelo processo de apartação de mulheres e homens da genericidade humana.

Neste sentido, este capítulo busca atualizar a centralidade do trabalho, a partir do pensamento de Marx e Lukács, como fundante da própria constituição do ser social, desenvolvendo uma aproximação crítica aos fenômenos que tendem a negar esta mesma centralidade na atualidade.

\section{FUNDAMENTOS ONTOLÓGICOS EM MARX E LUKÁCS: A CENTRALIDADE DO TRABALHO}

Na obra de Karl Marx (1818-1883), o trabalho é uma categoria medular e indispensável para a compreensão do ser social e das relações sociais. Ao longo de sua obra Marx apresenta a distinção entre o trabalho como categoria ontológica e o trabalho no modo de produção capitalista. Os estudos marxianos salientaram a particularidade do desenvolvimento capitalista em países como a Inglaterra, Alemanha e Estados Unidos da América, contudo, suas análises, do ponto de vista metodológico, seguem atuais e orientadoras para a compreensão do movimento essencial da ordem capitalista, bem como sua assimilação como relação social de produção (KONDER, 2009a; KONDER, 2009b; HARVEY, 2013).

A ontologia marxiana se constitui numa superação dialética de toda a cultura anterior radicalizando (no sentido de tomar pela raiz) as categorias centrais da razão moderna ao mesmo tempo em que aponta para uma concepção teórico-metodológica também radicalmente nova, que não sucumbe à pseudo-objetividade posta pelo movimento burguês.

Neste sentido, para Marx o método é a capacidade da razão de apreender o modo de ser e de se reproduzir da sociedade, nomeadamente do ser que lhe é próprio: o ser social. É este que impõe o método como caminho para se reproduzir idealmente a concretude real. Logo, entendemos que no pensamento marxiano a compreensão de qualquer momento do processo social requer que este seja articulado com a totalidade social, tendo como solo a produção social. Chasin é contundente nesse entendimento, quando analisa que, 
A crítica ontológica da economia política, em busca da 'anatomia da sociedade civil', leva à raiz, que impulsiona pelo nexo intricado das coisas, materialmente, à analítica da totalidade. Portanto, o ser social - do complexo da individualidade ao complexo de complexos da universalidade social - bem como sua relação com a natureza são alcançados e envolvidos, como já foi assinalado pelas irradiações consequentes à elevação das categorias econômicas ao plano filosófico na forma das categorias de produção e reprodução da vida humana. Com efeito, reconhecida em sua centralidade, essa problemática implica, desde a reconstituição da própria natureza enquanto tal e, em especial, diante da sociabilidade, até a precisa determinação, por exemplo, dos contornos da subjetividade. Em suma, posta em andamento, a crítica ontológica da economia política, ao contrário de reduzir ou unilateralizar, induz e promove a universalização, estendendo-se o âmbito da análise desde a raiz ao todo da mundaneidade, natural e social, incorporando toda a gama de objetos e relações (CHASIN, 1995, p. 380).

São estas relações que permitem a Marx, em 1857-1858, descortinar e, em 1867 expor, a visibilidade da ordem burguesa como processo em cujo horizonte é possível apreender o movimento do ser social como uma legalidade particularizada historicamente. Diferentemente dos economistas clássicos, Marx não partia do entendimento do homem tomado em si como ser extremamente egoísta e competitivo ${ }^{2}$. Para Marx, a visão naturalista destes pensadores é destituída de uma compreensão histórica do sujeito, onde a natureza humana aparece como imutável, o que não significa dizer que o ponto de partida em Marx não seja a própria imanência humana. Como explícito na "Ideologia Alemã”, “[...] o primeiro pressuposto de toda a história bumana é naturalmente a existência de individuos bumanos vivo. O primeiro fato a constatar é, pois, a organização corporal destes indivíduos e, por meio disto, sua relação dada com o resto da natureza" (MARX; ENGELS, 1999, p. 27 - Grifos nossos).

Dessa forma, Marx busca afirmar a análise do ser social a partir de algo empiricamente verificável, o fato real e incontestável da existência de indivíduos concretos, mais precisamente, não só de indivíduos concretos, mas de indivíduos que agem para se reproduzir. A afirmação ontológica de Marx gravita no sentido de apreender as determinações

\footnotetext{
${ }^{2}$ Esta concepção está presente em Hobbes (1983) e Maquiavel (1983).
} 
deste ser e na imposição posta ao mesmo para manter e preservar a sua existência.

Compreendemos, pois, que comparece neste autor a necessidade de uma reflexão que possibilite o entendimento daquilo que especifica a atividade humana - na realização de um salto operado pelo gênero humano em relação à dinâmica da natureza (inorgânica e orgânica) - e seus desdobramentos. O debate criticamente operado com Hegel e a interlocução fecunda com a economia política permite a Marx romper, de forma original, com as filosofias que o precederam e matizar seu caráter único no entendimento da atividade material como responsável pela autoconstrução do gênero humano.

Fica posto aqui, que este entendimento permite a Marx (2004) \{1846\} operar sua crítica radical a Feuerbach (1990) quando afirma que o ser social não é um ser passivo diante das determinações exteriores, ao contrário é um ser que por meio do trabalho - atividade humana fundamental e que permite a um determinado gênero de ser vivo destacar-se da legalidade natural e desenvolver-se segundo legalidades peculiares consegue romper com os limites postos por essa mesma natureza, diferenciando-se dela e passando a exercer uma atividade transformadora sobre a mesma.

O trabalho assume em Marx uma centralidade ontológica, posto que é fundante do ser social. Em outros termos, o trabalho é a primeira e mais importante forma de objetivação do ser social e, assim, se constitui devido a seu caráter ontologicamente primário de garantir as condições básicas que é a produção da vida material através do metabolismo homem-natureza e da constituição, a partir deste ato primário de relações entre os próprios homens.

Explicitamente, a função social do trabalho advém da relação material que o homem estabelece com a natureza para satisfação de suas necessidades, compreendendo a natureza como interior e externa ao homem na medida em que ele "[...] põem em movimento as forças naturais de seu corpo, braço etc.” (MARX, 1980, p. 202). Desta constatação inicial de que o homem se objetiva através do intercâmbio com a natureza, mediada pelo trabalho, se deduz que o homem é também um ser natural, 
e que este processo de intercâmbio com a natureza não a anula, mas a reconfigura.

Tais colocações nos remetem ao entendimento de que o desenvolvimento do ser social tem por base um ser orgânico, da mesma forma que um ser orgânico só pode se desenvolver a partir do ser inorgânico. Nestes termos, é o desenvolvimento mais complexo de cada esfera ontológica que determina uma reconfiguração e o alcance de uma maior complexidade no desenvolvimento da esfera inferior ao ser.

Dessa forma, Marx afirma que o homem tem uma relação de interdependência com a natureza, uma relação de continuidade e ruptura. O exato estabelecimento desta relação aparece neste autor na ênfase que ele confere à práxis humana. Entendida como atividade objetivo-criadora do ser social, a práxis só existe na medida em que relacionada a uma ação real e objetiva. Entendemos que Vázquez realiza uma devida explicitação daquela categoria marxiana quando este autor assinala que,

Marx ressalta o caráter real, objetivo, da práxis na medida em que transforma o mundo exterior que é independente de sua consciência e de sua existência. O objeto da atividade prática é a natureza, a sociedade ou os homens reais. A finalidade dessa atividade é a transformação real, objetiva, do mundo natural ou social para satisfazer determinada necessidade humana. E o resultado é uma nova realidade, que subsiste independente dos sujeitos ou dos sujeitos concretos que a engendraram com sua atividade subjetiva, mas que, sem dúvida só existe pelo homem e para o homem, como ser social (VÁZQUEZ, 1968, p. 194).

Como dito por Konder (2009a, p. 37 - Grifos nossos), "[...] no trabalho se encontra, por assim dizer, o 'caroço' da práxis; mas a práxis vai além do trabalho". Desse modo, ainda que os atos dos seres humanos não sejam restritos aos atos do trabalho, estes últimos permanecem como fundamento. Dessa forma, é através da práxis, que nos é possível posicionar adequadamente a articulação estabelecida por Marx entre mundo natural e social, sem que nos afastemos das particularidades de cada um. 
Logo, o entendimento do trabalho, em Marx, não é tido como meramente instintivo (atividade instintiva), mas sob forma exclusivamente humana (MARX, 1980, p. 202), assim como aparece posteriormente nos estudos de Lukács “[...] a essência do trabalho consiste precisamente em ir além dessa fixação dos seres vivos na competição biológica com seu mundo ambiente" (LUKÁCS, 1978, p.04).

A distinção da atividade realizada pelo homem, com relação aos outros animais dá-se justamente na teleologia (na projeção da ação). Ou seja, na intencionalidade que o homem atribui ao trabalho uma vez que "[...] ele figura na mente sua construção antes de transformá-la em realidade. No fim do processo do trabalho aparece um resultado que já existia antes idealmente na imaginação do trabalhador" (MARX, 1980, p. 202).

O processo de trabalho converte aquilo que aparece em forma de ideação em um produto (objeto), o que significa dizer que este produto sintetiza o mundo natural que existe realmente, que é transformado em objetos, mas que independe da consciência e a ideia previamente elaborada sobre o objeto a ser construído. Mais ainda, ao ser objetivada num objeto, a ideia passa a se constituir como parte da objetividade tornando a existir independente da consciência que o idealizou e sofre influências da evolução da realidade da qual passa a fazer parte (a causalidade).

Neste ponto, consideramos precisos os estudos de Lukács que avançam, tendo sempre como referencial as indicações de Marx. Na obra "Ontologia do Ser Social: os princípios ontológicos fundamentais em Marx” (1979), o filósofo húngaro ressalta que, diferentes modos de interpretar a posição radical - onde todo existente deve ser sempre objetivo, ou seja, deve ser parte movida e movente de um complexo concreto - levaram à falsa ideia de que Marx subestimava a importância da consciência com relação ao ser material, ou no entendimento habermasiano que Marx não atentou devidamente para as pertinências da dinâmica entre

\footnotetext{
${ }^{3}$ Tal entendimento tão bem expresso na célebre passagem de o Capital, quando Marx desenvolve a questão nos seguintes termos: pressupomos o trabalho numa forma em que pertence exclusivamente ao homem. Uma aranha executa operações semelhantes às do tecelão, e a abelha envergonha mais de um arquiteto humano com a construção dos favos de suas colmeias. Mas o que distingue, de antemão, o pior arquiteto da melhor abelha é que ele construiu o favo em sua cabeça, antes de construí-lo em cera. No fim do processo de trabalho obtém-se um resultado que já no início deste existiu na imaginação do trabalhador, e, portanto, idealmente (MARX, 1980, p.298).
} 
trabalho e interação, limitando a racionalidade da ontologia marxiana a uma razão teleológica ou estratégica ${ }^{4}$.

Lukács assevera no devido entendimento da obra marxiana quando estabelece que para uma filosofia evolutiva materialista (a de Marx) entender a consciência "[...] como um produto tardio do desenvolvimento do ser material, ao contrário não é jamais necessariamente um produto de menor valor ontológico" (LUKÁCS, 1978, p. 03). Ao contrário, para Lukács é justamente na delimitação materialista entre mundo natural e ser social que Marx confere à consciência papel extremamente decisivo. Não há em Marx nenhuma redução das objetivações ao trabalho e nem uma derivação mecânica das objetivações ao mesmo. O processo de trabalho é tão-somente a objetivação ontológica primária; ineliminável, que comporta outras objetivações e delas se realimenta.

Em Lukács estão desenvolvidas as indicações marxianas a respeito do trabalho como sendo o ato ontológico primário que estabelece uma articulação do sujeito com o objeto sendo que a realização se dá por meio do trabalho como uma síntese entre teleologia e causalidade.

De maneira precisamente demarcada pela obra marxiana, Lukács designa "[...] o homem que trabalha, ou seja, o animal tornado homem através do trabalho, como um ser que dá respostas" (LUKÁCS, 1978, p. 05). Para este autor, toda atividade laborativa só surge porque foi movida para dar solução a um carecimento. Neste movimento, os carecimentos são transformados em perguntas, o que, por sua vez, pressupõe um processo de captura, assimilação e desassimilação da realidade imediata através de demandas as quais se devem dar respostas. Este processo aponta para o entendimento lukacsiano das generalizações, ou seja,

[...] o homem torna-se um ser que dá respostas precisamente na medida em que - paralelamente ao desenvolvimento social e em proporção crescente - ele generaliza, transformando em perguntas seus próprios carecimentos e suas possibilidades de satisfazê-los; e quando em sua resposta ao carecimento que a provoca, funda e enriquece a própria atividade com tais mediações frequentemente bastante articuladas. De modo que não apenas a resposta, mas

\footnotetext{
${ }^{4}$ É Netto (1994) quem sinaliza tal equívoco analítico na obra habermasiana.
} 
também a pergunta é um produto da consciência que guia tal atividade (LUKÁCS, 1978, p. 05).

Em Lukács, o homem que trabalha é um ser que dá respostas às suas necessidades imediatas. Porém, estas respostas imediatas fazem parte de toda atividade laborativa e é justamente para superar esta relação imediata que estas respostas são elevadas ao nível da consciência (tanto as necessidades como as formas de satisfazê-las) e neste movimento a atividade fica enriquecida por mediações bastante articuladas, não havendo qualquer estagnação ou casuísmo. Em outros termos, é com a consciência, atuando através de generalizações, formando conceitos que o homem dá respostas ideais que servirão de guia e conduzirão a sua atividade. A generalização é assim, o momento onde a realidade imediata é vertida na consciência a conceitos abstratos que, por sua vez, são vertidos em instrumentos que podem atender a fins conscientes ${ }^{5}$.

Logo, a posição teleológica é entendida como o estabelecimento consciente de fins a serem alcançados. No entanto, estas finalidades não podem ser derivações mecânicas ou fenômenos secundários da realidade material, mas devem ser tomadas como socialmente criadas e formadas de maneira consciente pelo sujeito.

Dessa forma, evidenciamos que as finalidades não são criações autonomizadas do sujeito, tanto porque se constitui como resposta a um carecimento objetivo, ou seja, a objetividade põe o espaço no qual é possível ao sujeito realizar os fins, como também porque é um equívoco pensar o sujeito como um produto em si, posto que ele é um produto social, um sujeito-singular que é fruto de uma formação social dada.

Lukács é enfático quanto à compreensão de que as posições teleológicas mesmo que livres, encontram um campo de possibilidades material e subjetivamente configurado, ou seja, a causalidade "[...]

\footnotetext{
${ }^{5}$ A satisfação das necessidades - enquanto elemento ontologicamente primário - não são anuladas. É este carecimento material, que põe em movimento, para a reprodução individual e coletiva, o complexo do trabalho e todas as mediações que existem em função da sua satisfação, mas isso não nega o fato de que esta satisfação opera-se com uma cadeia de mediações que transformam tanto a natureza como o homem, porque tornam eficientes as forças, relações e qualidades da natureza (que não poderia fazer isso por si) de modo que, o homem passa a desenvolver suas próprias capacidades em níveis mais altos que superam o simples fazer.
} 
representa a lei espontânea na qual todos os movimentos de todas as formas de ser encontram a sua expressão geral" (LUKÁCS, 1978, p. 06). A causalidade possui um princípio próprio de movimento - observado, sobretudo nas leis da natureza - donde sua evolução acontece na absoluta ausência de consciência, ainda que a consciência possa, através do trabalho, interferir na sua evolução. Contudo, o momento ontológico do trabalho impõe-se como uma ação nova que modifica o curso da causalidade natural, pondo esta última a se desenvolver em articulação complexa com outro tipo de ser - o ser social.

Nestes termos, mesmo que o ser social efetive a fundação de leis próprias de desenvolvimento, toda práxis social contém em si um caráter contraditório: por um lado, tem-se que a práxis só se efetiva mediante a realização de escolhas. No dizer de Lukács “[...] todo ato social surge da decisão de alternativas acerca de posições teleológicas futuras, por outro lado, a necessidade social só se pode afirmar por meio da pressão que exerce sobre os indivíduos frequentemente de forma anônima" (LUKÁCS, 1978, p. 06).

Logo, na teoria marxiana do desenvolvimento histórico, os aspectos teleológicos do processo foram justamente estabelecidos apenas como pertinentes à categoria trabalho, isto é, à teleologia cabe movimentar séries causais, determinando na medida em que se objetiva, um novo tipo de processualidade - a causalidade posta ou social. Esta última possui leis tendenciais de desenvolvimento que, mesmo que complexamente articuladas ao mundo natural, não se confundem nem tampouco se identificam com os nexos causais puramente naturais.

A compreensão marxiana de trabalho não tem em mente apenas o indivíduo que a realiza, mas sobre este trabalho individual está operada também uma dimensão histórico-social (a totalidade social). Posto isso, entendemos que a concepção burguesa de mundo que afirmou a dimensão histórica do mundo dos homens, não conseguiu apreender o real alcance do núcleo fundamental do ser social, ou seja, o fundamento econômico. Para a concepção burguesa de mundo, a história é naturalizada e as ações humanas, por mais positivas que possam vir a ser, não são capazes de modificá-la. E, dessa forma, no mundo burguês as possibilidades 
humanas de realização da história ficam limitadas ao horizonte do fenomênico, onde apenas este patamar é passível de modificações.

Em radical oposição a análise marxiana, por sua vez, situa a historicidade como única categoria universal presente tanto no mundo natural como no mundo do ser social, cuja essência ${ }^{6}$ se apresenta como mutável. Nesta captura da natureza histórica da essência, o pensamento marxiano, desloca os fundamentos da apreensão do mundo burguês, que tanto tende a generalizar a essência do homem burguês à condição de essência burguesa do homem como também, estabelece uma dualidade entre essência imutável e esfera fenomênica sujeita a modificações.

Ao contrário, em Marx e Lukács a essência é parte integrante de toda a processualidade. Logo, o fundamento da distinção marxiana entre essência e fenômeno está na continuidade e não num quantum maior ou menor de ser que cada uma dessas esferas é capaz de comportar. A essência é, pois, portadora de uma continuidade histórica que não se observa nos atos fenomênicos. No dizer de Lessa (2002, p. 57), a essência, portanto é o lócus da continuidade.

Significa dizer que tanto a essência como o fenômeno são resultantes de atos humanos singulares e históricos. Isto significa, afirmar primeiro, que a esfera da essência está submetida às ações humanas e, em segundo lugar, que a esfera fenomênica não é mera adaptação passiva ao desdobramento de uma necessidade essencial - o que implica dizer que os fenômenos têm papel ativo na explicitação do ser social. Nestes termos, o processo que se efetiva entre essência e fenômeno é de interrelação, e não de sobreposição, ou unilateralização, como quer o horizonte burguês.

\footnotetext{
${ }^{6}$ Neste ponto de nossas análises, sinalizamos que a concepção de essência de Marx e desenvolvida por Lukács é radicalmente diversa ao entendimento burguês, na medida em que demonstra que essência e fenômeno são compósitos articulados e constituídos no desenvolvimento do processo histórico. Aqui incorporamos as argumentações de Lessa, consideradas polêmicas, mas que no nosso entendimento buscam alcançar o máximo de coerência com o núcleo analítico lukacsiano. Para este autor, "[...] o ser é histórico porque sua essência, em vez de ser dada a priori, se consubstancia ao longo do próprio processo de desenvolvimento ontológico. Em lugar de determinar o processo exterior, a essência em Lukács é parte integrante e imprescindível de toda a processualidade" (LESSA, 2002, p. 51). Precisamente quando fazemos tal afirmação, estamos ancorando nossa argumentação nas considerações pertinentes desenvolvidas por Lessa, uma vez que para este autor "o ser é histórico porque sua essência, em vez de ser dada a priori, se consubstan cia ao longo do próprio processo de desenvolvimento ontológico" (LESSA, 2002, p. 51).
} 
Nestes termos, há uma clara determinação reflexiva entre subjetividade e objetividade na ontologia marxiana, posto que o indivíduo que realiza objetivações modifica e enriquece a objetividade, no mesmo processo altera de forma cada vez mais complexa a sua própria subjetividade. Este fato leva a compreender que o produto do trabalho humano possibilita o desenvolvimento não só do homem, mas de toda a sociedade; decorrente que é de um processo de acumulação constante de conhecimento que passa do caso singular para a generalidade.

Em outras palavras, todo ato humano possui uma insuprimível dimensão genérica, coletiva. Em primeiro lugar, porque o novo ato é também resultado da história passada, é a expressão do desenvolvimento anterior de toda a sociedade. Em segundo lugar, porque o novo objeto promove alterações na situação histórica concreta em que vive toda a sociedade; este agora possui novas possibilidades e necessidades. O novo objeto participa do desenvolvimento futuro. E em terceiro lugar, os novos conhecimentos adquiridos se generalizam em duas dimensões: tornam-se conhecimentos aplicáveis às situações mais diversas e transformam-se em patrimônio genérico de toda a humanidade, na medida em que todos os indivíduos passam a compartilhar do mesmo.

Assim, os indivíduos ganham cada vez mais dimensão genérica e universal na medida em que se apropriam da cultura material cristalizada pelas objetivações humanas. Tal é esta relação que quanto mais ricas forem estas objetivações e quanto mais ampla for a apropriação humana da cultura material e espiritual, mais complexo é o desenvolvimento das individualidades. Como explicitado por Lukács,

A individualidade já aparece como uma categoria do ser natural, assim como o gênero. Esses dois pólos do ser orgânico podem se elevar à pessoa humana e o gênero humano no ser social tão-somente no processo que torna a sociedade cada vez mais social. [...] Tarefa de uma ontologia tornada histórica é, ao contrário, descobrir a gênese, o crescimento, as contradições no interior do desenvolvimento unitário; é mostrar que o homem, como simultaneamente produtor e produto da sociedade, realiza em seu ser-homem, algo mais elevado que ser simplesmente exemplar de um gênero abstrato, que o gênero - nesse nível ontológico, 
no nível do ser social desenvolvido não é mais uma mera generalização à qual os vários exemplares se ligam 'mudamente' (LUKÁCS, 1978 p. 13).

Este movimento evidencia que o indivíduo singular carrega em si as determinações universais, de modo que pensar indivíduo e gênero numa lógica de prevalência de um sobre o outro é um equívoco, que no mundo burguês, acaba por revestir-se na funcionalidade de conferir caráter universal às particularidades de formações sócio-histórico concretas.

Deste modo, a radicalidade da ontologia marxiana centrada no processo de autoconstrução humana expõe todas as nuances do caráter alienante e não realizador do homem que se verificam no processo de apropriação que se realiza, sob o jugo burguês, na divisão social do trabalho, na propriedade privada e no desenvolvimento das relações mercantis. Como bem posto por Lukács,

Só quando o trabalho for efetivamente e completamente dominado pela humanidade e, portanto, só quando ele tiver em si a possibilidade de ser 'não apenas meio de vida' mas o 'primeiro carecimento da vida' só quando a humanidade tiver superado qualquer caráter coercitivo em sua própria autoprodução, só então terá sido aberto o caminho social da atividade humana como fim autônomo. (LUKÁCS, 1978, p. 16).

O desenvolvimento do ser social tem significado crescente diferenciação interna das sociedades, o que implica dizer que novas contradições vão sendo introduzidas na dinâmica social na medida em que aumenta a sua complexidade. Por outro lado, está denotado que quanto maior for o desenvolvimento da complexidade social maior será a exigência para que a ação dos indivíduos seja cada vez mais complexa.

A historicidade - já sinalizada anteriormente - que comparece no pensamento marxiano "[...] é sempre a historicidade de um complexo" (NETTO, 1994, p. 38) que se movimenta por meio da negatividade que atravessa os complexos que a constituem. Este movimento é claramente sumariado por Netto na seguinte assertiva,

A totalidade concreta só é dinâmica enquanto portadora de uma negatividade imanente que a processualiza - uma totalidade sem negatividade é uma totalidade morta. Mas a historicidade não se 
conforma num unilinear: em cada totalidade constitutiva da totalidade social concreta, a negatividade que a dinamiza refrata-se de acordo com as suas particularidades - a negatividade se realiza no marco de um sistema de mediações que responde, no movimento da totalidade social concreta, pelo desenvolvimento desigual das suas totalidades constitutivas. Assim, a totalidade concreta (como suas componentes) é dinamizada através de mediações - uma totalidade imediata é uma totalidade amorfa, inestruturada (NETTO, 1994, p. 38 - Grifos nossos).

Assim, ao mesmo tempo em que é o processo de trabalho que complexifica o ser social, esta mesma complexificação remete a problemas e necessidades que não podem ser resolvidas no interior dele. Daqui resulta a gênese de outros complexos, cuja função é a resolutividade das questões postas, originando outras esferas do ser social como é o caso da educação, da política, do direito, das artes. Dessa forma, o novo modo de ser - o social - inaugurado pelo trabalho - que põe o ato teleológico - possibilita-nos demarcar que a ontologia marxiana capta a essência daquilo que é próprio da estrutura do ser social: o seu caráter de totalidade. Uma realidade social constituída de complexos de complexos, que não pode ser pensada como um "organismo" que é composto de partes que se complementam, mas como um sistema histórico-concreto de relações entre totalidades que se estruturam segundo grau de complexidade.

\section{BREVES ANOTAÇÕES ACERCA DA ALIENAÇÃO, FETI- CHISMO E REIFICAÇÃO}

O fenômeno da alienação ${ }^{7}$, enquanto manifestação social, pode ser verificado anteriormente à existência da produção mercantil. Particularmente nas sociedades em que se verifica a apropriação privada do excedente econômico.

Um exemplo claro disso pode ser encontrado na existência social do camponês europeu da Idade Média. Neste período a experiência indi-

\footnotetext{
${ }^{7}$ A alienação, enquanto conceito em si mesmo, abarca uma multiplicidade de fenômenos e processos em épocas histórico-sociais diferentes e tem uma história vasta e complexa de desenvolvimento que vai desde a Bíblia, a trabalhos literários, passando por tratados sobre economia, direito e filosofia. Para uma boa panorâmica sobre o tema Mészáros, 2006; Schaff, 1979.
} 
vidual, o ritmo de vida, a mobilidade espacial não permitia a constituição de fronteiras claras entre a esfera social e a esfera natural.

Estes desenvolvimentos evidenciam que os processos alienantes existentes nas dinâmicas sociais anteriores ao capitalismo engendravam representações que a sociedade constituía com a natureza. Mais ainda, explicita que o baixo grau de desenvolvimento das forças produtivas acarretava uma sacralização do mundo extra-humano e um consequente misticismo que envolvia o metabolismo sociedade/natureza.

É o advento da moderna sociedade burguesa responsável pela socialização da sociedade (por meio do desenvolvimento, implementação e expansão tecnológica no/do processo de produção e da sua planetarização por meio do mercado mundial ${ }^{8}$ ) que contribui efetiva e crescentemente para a desantropomorfização da realidade. ${ }^{9}$

Contudo, este sentido inteiramente progressista do capitalismo em ascendência passou a ser amplamente questionado entre 1830-1848. Neste período, assinala-se o acirramento das contradições do mundo burguês, pois, são o próprio desenvolvimento do capitalismo e a consolidação da dominação burguesa que engendram as forças organizativas do movimento operário, emergentes neste momento de crise.

Nesse processo a sociedade burguesa alicerça uma forma própria de alienação, diferente de suas formas arcaicas. Assumindo mecanismos concretos e particulares que não possibilita equalizá-los a períodos históricos anteriores. Mais precisamente se opera "[...] abrigando e recolhendo as antigas formas de alienação, (num primeiro momento instrumentalizando-as) para repô-las em outro nível - justamente o engendrado pelo fetichismo" (NETTO, 1981, p. 71) e que redundam em formas alienadas específicas as reificadas.

Em outras palavras, significa compreender que: ao mesmo tempo em que a constituição, o desenvolvimento e a expansão da sociedade capitalista estabelece para o ser social o mais alto grau de desenvolvimento

\footnotetext{
${ }^{8}$ Marx e Engels são muito precisos quanto a isso. Em várias e belas passagens do "Manifesto do Partido Comunista" referenciam o caráter histórico-revolucionário da burguesia.

${ }^{9}$ Identificar essa processualidade não significa, contudo, desconsiderar que a construção dessa modernidade e de seu projeto contraditoriamente se desenvolveu por meio da violência e subordinação social-cultural dos territórios "colonizados" e de seus povos (DUSSEL, 1995). A decorrência analítica desse processo, leva entre outras determinações a configuração da dependência como marca da formação social brasileira, por exemplo.
} 
ao qual se alçaram as relações sociais, contraditoriamente os processos alienantes e as representações alienadas presentes nesta ordem possuem uma matriz, uma estrutura, uma funcionalidade e uma significação que se desenvolvem expressando um “[...] caráter estritamente social” (NETTO, 1981, p. 79).

É Marx - quando efetua sua crítica da economia política numa perspectiva medularmente ontológica a partir de $1857-1858^{10}$ - quem formula a mais radical análise acerca desta questão. Em seu movimento de capturar a essencialidade dos fenômenos para entender a sociabilidade burguesa, Marx localiza na mercadoria não apenas a célula econômica da sociedade capitalista, mas também e principalmente a matriz que contém e escamoteia a raiz dos processos alienantes que tem curso na mesma. No dizer de Marx, a mercadoria apreendida em sua imediaticidade não é capaz de revelar sua lógica interna e imanente, o seu proceder.

É fato, que no desenvolvimento anterior das sociedades a troca de mercadorias já se encontrava presente. Contudo, é somente na sociedade capitalista que esta troca se torna capaz de penetrar no conjunto das dimensões sociais uma vez que, torna-se a pedra de toque de uma organização social onde toda a estrutura produtiva e reprodutiva está articulada para a sua exclusiva obtenção.

$\mathrm{Na}$ ordem burguesa, enquanto modo particular de produção, isto acontece quando a troca assume uma forma expansiva, onde "se produzam às coisas úteis para serem permutadas, considerando-se o valor das coisas já por ocasião de serem produzidas" (TEIXEIRA, 2000, p. 82). No entanto, reside aqui uma contradição ineliminável da ordem do capital, qual seja: "[...] a criação e a expansão das necessidades humanas só podem realizar-se sob a forma de mercadorias" (TEIXEIRA, 2000, p. 69).

\footnotetext{
${ }^{10}$ Existe uma ampla polêmica acerca do desenvolvimento marxiano em torno da questão alienação: Uma primeira, que refuta a permanência da teoria da alienação no conjunto da obra de Marx; e uma segunda que insiste na continuidade da teoria da alienação no conjunto da obra e, especialmente, na sua relação com a problemática do fetichismo. Neste campo as nuances também são diferenciadas. Há aqueles que consideram que a teoria da alienação nas obras de Marx de 1844 e em 1857-1858 é a mesma (SCHAFF, 1979); outros que consideram que desde os primeiros escritos comparece uma teoria da reificação (MARCUSE, 1979), etc. Nas nossas análises, compreendemos que de um lado, a problemática da alienação atravessa toda a obra de Marx, e, de outro que não se trata de um novo conceito de alienação.
} 
Assim, a contradição, em resumo, reside, pois na universalização cada vez maior (operando em larga escala) da produção de valores de uso, que ao mesmo tempo, só se tornam passíveis de serem produzidos se atenderem à necessidade de valorização do valor.

Este processo apresenta-se fortemente marcado por uma racionalização, que destrói as propriedades qualitativas, humanas e individuais do trabalhador (LUKÁCS, 2003). Este movimento de racionalização, por sua vez não está presente apenas no processo de trabalho, que passa por uma intensa fragmentação transformando-se em operações parciais abstratamente racionais; também incide sobre o trabalhador na medida em que rotiniza seu trabalho a execução de funções especializadas e repetidas mecanicamente. ${ }^{11}$

Este princípio efetiva-se numa brutal fragmentação do objeto e do sujeito: pelo objeto, na medida em que se rompe com a unidade orgânica que articula o produto como objeto do processo de trabalho. Do ponto de vista do sujeito, a fragmentação do objeto leva necessariamente a sua fragmentação. O homem deixa de aparecer como o verdadeiro portador do processo de trabalho, este agora está sob o domínio de leis abstratas e calculadas previamente que apenas incorporam o homem ao seu sistema mecânico.

Dessa forma, a consciência reificada é para Lukács, aquela que transforma as formas do capital, nos verdadeiros representantes da vida social, de modo que a consciência, submetida às condições da divisão social do trabalho acaba perdendo "[...] toda a imagem da totalidade" (LUKÁCS, 2003, p. 228).

Por isso, quando Marx procura entender de onde provém o caráter misterioso que o produto do trabalho humano apresenta ao assumir a forma mercadoria, elabora em sua resposta o problema do fetichismo. Ou seja, é da própria forma da mercadoria que decorre este mistério. Os produtos parecem ter valores próprios e por si só, ou seja, é fetichizada a forma que confere valor ao produto do trabalho.

Em outras palavras, por fetichismo da mercadoria deve-se entender não apenas a ilusão de que as mercadorias parecem deter

\footnotetext{
${ }^{11}$ Marx explicita detalhadamente este processo no Capital, ao analisar a cooperação, manufatura e grande indústria.
} 
propriedade inata de estabelecer relações de produção entre os homens, mas também, o fato de que essa ilusão nasce do processo de vida real dos indivíduos, da forma de organização da produção social. Deste modo entendemos que, o mecanismo do fetichismo que é pertencente ao universo da produção mercantil “[...] responde, pois, por um modo de emergência de aparição, de objetividade imediata do ser social que o inverte: fá-lo aparecer como factualidade - o que é relação social se mostra como relação objectual" (NETTTO, 1981, p. 41).

Assim, fica-nos evidente que existe uma relação entre fetichismo e alienação - na medida em que o fetichismo se manifesta nas formas de vivência e representações alienadas. Isto, por outro lado não significa que fetichismo e alienação se confundam ou se identifiquem. Como fica límpido na obra marxiana, especificamente nos textos de 1859 e 1867, o fetichismo é uma forma particular de alienação, ou seja, exprime a forma mais desenvolvida da alienação nas relações sociais sob o capitalismo. Contudo, isto não esgota o fenômeno da alienação que, por ser mais amplo pode ser político, religioso, ideológico, etc. Por outro lado, quando Marx desvenda o enigma do fetichismo ele apreende a estrutura específica que a alienação adquire na sociedade burguesa constituída: a reificação. ${ }^{12}$

Para a produção capitalista de bens de consumo, o cotidiano é um polo que deve receber a devida atenção. O melhor exemplo disso fica com as técnicas de publicidade, que se por um lado introduzem na vida cotidiana o fabuloso reino das máquinas, dos utensílios domésticos, por outro, também são responsáveis por realizarem uma sedução permanente ao prático, ao pragmático, ao mágico, ao ilusório. A vida cotidiana torna-se o espaço privilegiado para a modelagem do homem positivo, àquele para o qual não apenas o seu trabalho e o produto dele são estranhos, mas a sua própria existência é direcionada por uma instância alheia. Trata-se, como bem retrata Netto (NETTO, 1981, p. 41), de uma pseudo-objetividade que repercute na sociedade como uma aparente naturalidade das relações sociais.

\footnotetext{
${ }^{12}$ Ou no dizer de Schaff "[...] as duas teorias (fetichismo e reificação) referem-se à mesma coisa, só que a teoria do fetichismo considera esta situação a partir da mercadoria [...] a teoria da reificação [...] a partir das relações inter-humanas" (SCHAFF, 1979, p. 127).
} 


\section{CONSIDERAÇÕES FINAIS, AINDA SOBRE A ATUALIDADE}

Você deve notar que não tem mais tutu

E dizer que não está preocupado

Você deve lutar pela xepa da feira

E dizer que está recompensado Você deve estampar sempre um ar de alegria

E dizer: tudo tem melhorado

Você deve rezar pelo bem do patrão

E esquecer que está desempregado

"Comportamento Geral" - Gonzaguinha

Vivemos (sobrevivemos) sob a lógica revigorada e atualizada do sistema capitalista, que passa por várias metamorfoses e permanece, hoje como ontem, baseando-se na propriedade privada e na apropriação privada do excedente. Esta atualização se dá a partir de um amplo processo de reconfiguração do capitalismo mundial balizada na esfera da produção pela chamada reestruturação produtiva e num novo regime de acumulação mundial predominantemente financeiro.

Do ponto de vista político esta atualização sustenta-se no neoliberalismo, cuja essência é o afastamento dos obstáculos à circulação do fluxo de mercadorias e dinheiros, pela via da contrarreforma do Estado. Esse é o quadro geral da ofensiva capitalista sob o trabalho, acarretando diversas perdas políticas e sociais para a classe trabalhadora, contribuindo, dessa forma, para a fragmentação político-organizativa dos trabalhadores.

O que se observa é que os debates e produções teóricas não têm desenvolvido suficiente este tema (FREDERICO, 1997). Mais do que isso se verifica a ausência de determinadas categorias analíticas fundamentais para pensarmos o presente (e o futuro), tais como as categorias de alienação, reificação e fetichismo. Em certa medida, a explicação para esta ausência está ligada primeiramente a redução da vida social à esfera da singularidade e da superficialidade o que acarreta um grave obscurecimento dos elementos que mediatizam a aparência e a essência dos fenômenos sociais.

Quando Konder (2009b) discute a relação entre alienação e história, o faz apresentando a alienação como condensação de um processo 
histórico que articula a divisão social do trabalho, a propriedade privada e as classes sociais. O autor também assevera que "[...] a consciência divorciada da prática marca, no homem, a alienação” (KONDER, 2009b, p. 65). Estes escritos de Konder (que foram publicados pela primeira vez em 1965, seu primeiro livro) permanecem atuais e contribuem com a leitura do tempo presente. Konder nos fala da institucionalização de um estado em que indivíduos (que são dependentes da coletividade) só defendem seus interesses particulares, dissociando-se dos interesses de outros indivíduos que compõem a mesma coletividade que habitam. Trata-se, conforme o autor, de uma sociabilidade que cria contradição permanente (KONDER, 2009b, p. 67).

Retornemos a Cleonice (trabalhadora que abre nosso texto) e a pandemia. Em síntese o conceito de pandemia é o de disseminação mundial de uma nova doença, ou seja, algo que afeta todo o planeta. Cleonice possivelmente não leu Marx, Lukács ou Konder, mas é de Cleonices que a crítica ontológica às relações sociais no capitalismo trata. A pandemia, assim como a crise, é global, mas os efeitos perniciosos - da crise e da pandemia - reincidem sobre a classe trabalhadora. Os efeitos não recaem sobre todos/as da mesma maneira.

A crítica à economia política realizada pela obra marxiana, dentre outros aspectos, produziu a concretização dos fatos econômicos, analisados à luz da totalidade das relações sociais historicamente construídas. Esta não é uma afirmação intelectual abstrata, é esta afirmação que nos ajuda a entender (sem explicações místicas) as condições de vida e a morte de Cleonice.

A pandemia da COVID-19, assim como as crises cíclicas do capital (MANDEL, 1982), nunca foi democrática por atingir todos/as. Partir dessa ideia de democrático retira a estrutura de classes presente na determinação social do processo saúde-doença.

O estudo realizado pelo Núcleo de Operações e Inteligência em Saúde (NOIS) da PUC-Rio, divulgado através da Nota Técnica $11 / 2020^{13}$, traz dados para essa discussão. A pesquisa trata da “Análise

\footnotetext{
${ }^{13}$ A Nota Técnica encontra-se na íntegra disponível em: $<$ https://drive.google.com/file/d/1tSU7mV4OPnLRFMMY47JIXZgzkklvkydO/view $>$. Acesso em: 3 out. 2020.
} 
socioeconômica da taxa de letalidade da COVID-19 no Brasill", os achados do estudo apontam que, no caso brasileiro, a progressão da doença foi influenciada também pelos fatores socioeconômicos.

A pesquisa realizada pelo NOIS analisou a variação da taxa de letalidade $^{14}$ da COVID-19 no Brasil considerando variáveis socioeconômicas.. O estudo identificou que pretos e pardos morrem mais de COVID19 do que brancos. Tomando por base o elemento desigualdade de acesso ao tratamento o estudo apontou que as chances de morte de um indivíduo preto ou pardo não alfabetizado são 3,8 vezes maiores do que de um paciente branco com nível superior. Quando observado somente da questão étnico-racial na avaliação dos óbitos ${ }^{15}$ os achados apontam que $55 \%$ dos pretos e pardos faleceram, já entre os brancos esse percentual foi de 38\%. Na avaliação por faixa etária em todas as faixas os pretos e pardos apresentaram um número maior de óbitos em relação aos brancos.

Outro achado da pesquisa foi a constatação de que quanto maior a escolaridade, menor a letalidade da COVID-19. Os resultados foram de que os sem escolaridade tiveram percentuais três vezes superiores $(71,3 \%)$ aos que têm nível superior $(22,5 \%)$.

Quando o estudo realiza a combinação de raça com escolaridade, os óbitos de pretos e pardos foram em maior proporção em todos os níveis de escolaridade se comparados aos brancos. Com destaque para a comparação entre pretos e pardos sem escolaridade e brancos com nível superior, quando se observa essa relação os pretos e pardos têm uma proporção de quatro vezes maior de morte. Este estudo aponta o caráter não democrático da mortalidade por COVID-19 no Brasil. Revela seu caráter de classe, revela as marcas da particularidade brasileira e revela ontologicamente que é a condição de trabalhadoras/os assalariados/as que explica por que suas vidas não estão preservadas.

\footnotetext{
${ }^{14}$ Conforme a Nota Técnica refere-se ao "[...] número total de óbitos dividido pelo total de casos com desfecho, isto é, casos onde o paciente teve alta ou veio a óbito". Os pesquisadores avaliaram 30 mil casos encerrados das notificações de Síndrome Respiratória Aguda Grave confirmadas para COVID-19.

${ }^{15}$ Como aponta a Nota Técnica quase dez mil se identificaram como brancos e quase nove mil como pretos e pardos.
} 
Ao mesmo tempo entre as/os trabalhadoras/es a submissão às condições de alienação é o que também explica e atualiza a necessidade de mediatizar as categorias alienação, fetichismo e reificação com as condições atuais em que as Cleonices estão apartadas da genericidade. E, explica também porque todas/todos estão em eterno conflito por manter sua posição no mercado de trabalho, com COVID-19 e com tudo. Suprimidos da capacidade de se reconhecer como agente da modificação real e objetiva da vida por meio do trabalho a conformação subjetiva de quem trabalha está fragmentada, e, o trabalho, não passa de mero meio de vida (o mando do patrão). A propriedade privada deturpa o fluxo produtivo, carregando na ideia de "posse" - de "ter" - seu caráter desumanizador e assim atravessa a vida imediata de ideologias e sensos comuns que não nos deixam respirar. Nas palavras de Marx, "[...] a atividade do trabalhador não é a sua autoatividade. Ela pertence a outro, é a perda de si mesmo" (MARX, 2004, p. 83).

Assim, para superar este estado de coisas precisamos seguir na batalha das ideias, tornando-as inteligíveis para assim municiar a luta real e concreta, ou seja, as mediações que se atualizam no existir das Cleonices. E são as categorias ontológicas que nos permitem superar esse abismo entre a produção humano-genérica e a participação consciente do indivíduo nesta produção, nos fazendo avançar na construção de uma sociabilidade outra, pois, como nos advertiu $\operatorname{Konder~(1997,~p.~44):~“[...]~a~rea-~}$ lidade é muito mais do que o existente, porque ela é o existente mais o possível".

\section{REFERÊNCIAS}

CHASIN, J. Marx - estatuto ontológico e resolução metodológica (posfácio). In: TEIXEIRA, F. J. S. Pensando com Marx: uma leitura comentada de O Capital. São Paulo: Ensaio, 1995.

DUSSEL, H. 1492: El encubrimiento del Outro: hacia el origen del mito de la Modernidad. La Paz: Plural Editores, 1995. 
FANTASTICO. Portal G1. Disponível em: $\leq$ https://g1.globo.com/fantastico/noticia/2020/03/22/uma-pessoa-muito-batalhadora-diz-sobrinho-de-empregada-domestica-que-morreu-de-coronavirus.ghtml $>$. Acesso em: 06 out. 2020.

FEUERBACH, L. A Essência do Cristianismo. 2. ed. São Paulo: Papirus, 1990.

FREDERICO, C. Razão e desrazão: a lógica das coisas e a pós-modernidade. Serviço Social \& Sociedade, ano XVIII, n. 55, p. 174-187, jul. São Paulo: Cortez. 1997.

HARVEY, D. Para entender O Capital. Livro I. São Paulo: Boitempo, 2013.

HOBBES, T. Leviatã ou matéria, forma e poder de um Estado eclesiástico. Coleção Os Pensadores. 3. ed. São Paulo: Abril Cultural, 1983.

KONDER, L. O Trabalho e a Crise da Modernidade. O Social em questão, Rio de Janeiro, v. 1, n. 1, p. 39-50, 1997.

A derrota da dialética: a recepção das ideias de Marx no Brasil, até o começo dos anos 30. São Paulo: Expressão Popular, 2009a.

. Marxismo e Alienação: contribuição para um conceito marxista de alienação. São Paulo: Expressão Popular, 2009b.

LESSA, S. Mundo dos Homens: trabalho e ser social. São Paulo: Boitempo, 2002.

LUKÁCS, G. As bases ontológicas do pensamento e da atividade do homem. Revista Temas de ciências Humanas, n. 4, p. 1-18, São Paulo: Ciências Humanas. 1978. 
Ontologia do ser social: os princípios ontológicos fundamentais de Marx. São Paulo: Ciências Humanas, 1979.

. História e Consciência de Classe: estudos sobre a dialética marxista. São Paulo: Martins Fontes, 2003.

MANDEL, E. O capitalismo tardio. Col. Os economistas. São Paulo: Abril Cultural, 1982.

MAQUIAVEL, N. O Príncipe; Escritos Políticos. Coleção Os Pensadores. 3. ed. São Paulo: Abril Cultural, 1983.

MARCUSE, H. A ideologia da sociedade industrial: o homem unidimensional. 5. ed. Rio de Janeiro: Zahar. 1979.

MARX, K. O Capital. Livro I, V. I. 8. ed. São Paulo: Difel, 1980. . Manuscritos Econômicos-filosóficos. São Paulo: Boitempo. 2004.

MARX, K.; ENGELS, F. A Ideologia Alemã. 11. ed. São Paulo: HUCITEC, 1999.

MÉSZÁROS, I. A Teoria da Alienação em Marx. São Paulo: Boitempo, 2006.

NETTTO, J. P. Capitalismo e reificação. São Paulo: Ciências Humanas, 1981.

. Razão, ontologia e práxis. Serviço Social \& Sociedade, São Paulo, ano XV, n. 44, Abril, p. 26-42. 1994.

Núcleo de Operações e Inteligência em Saúde (NOIS) da PUC-Rio. Nota Técnica 11/2020. A Nota Técnica encontra-se na íntegra disponível em: <https://drive.google.com/file/d/ 
1tSU7mV4OPnLRFMMY47JIXZgzkklvkydO/view>. Acesso em: 3 out. 2020

SCHAFF, A. La alienación como fenômeno social. Barcelona: Crítica. 1979.

TEIXEIRA, F. J. S. O Capital e suas formas de produção de mercadorias: rumo ao fim da economia política. Crítica Marxista, São Paulo, n. 10, p. 67-94. 2000.

VÁZQUEZ, A. S. Filosofia da Práxis. Rio de Janeiro: Paz e Terra, 1968. 